\title{
Snow depths and grain-size relationships with relevance for passive microwave studies
}

\author{
RICHARD L. ARMSTRONG \\ CIRES/NSIDC, University of Colorado, Boulder, CO 80309, U.S.A.
}

Alfred Chang

Goddard Space Flight Center, Hydrological Sciences Branch, Greenbelt, MD 20771, U.S.A.

Albert Rango

USDA Hydrology Laboratory, Agricultural Research Service, Beltsville, MD 20705, U.S.A.

EDWARD JOSBERGER

U.S. Geological Survey, University of Puget Sound, Tacoma, WA 98416, U.S.A.

\begin{abstract}
The application of passive microwave radiometry to the remote sensing of snow properties is based on the ratio of emitted to scattered portions of the upwelling radiation. Increased scattering is indicative of increased snow amount, i.e. the number of snow grains present. However, scattering is also directly proportional to snow grain-size for a given snow amount. Current snow cover retrieval algorithms produce inaccurate results when snow grain-sizes are unusually large. Therefore, it is necessary to characterize snow grain-size on a regional scale (and perhaps local scale in extreme situations) in order to adjust passive microwave algorithms. Preliminary analysis indicates that: (1) algorithms are not as sensitive to the presence of large grain-sizes as the initial theory had indicated; (2) standard deviation of grain-size diameters throughout the total snow cover may often be less than $0.5 \mathrm{~mm}$, thus average grain-size data may often serve to characterize the detailed stratigraphy of the total snow cover; (3) conditions in subfreezing snow which produce grain-sizes that greatly exceed a mean diameter value of $1-2 \mathrm{~mm}$ result from snow cover/climate relationships which can be modelled/monitored on a regional scale. A preliminary method is investigated for selecting snow retrieval algorithms according to prevailing regional-scale grain-size.
\end{abstract}

\section{MICROWAVE EMISSION FROM SNOW}

At microwave frequencies $(1-300 \mathrm{GHz}$, or $30 \mathrm{~cm}$ to approximately $1 \mathrm{~mm}$ wavelength) it is customary to express the signal received by a passive microwave sensor in terms of brightness temperatures $\left(T_{\mathrm{b}}\right)$. Brightness temperature is expressed in units of temperature (Kelvin) because for wavelengths in the microwave region the radiation emitted from an object is proportional to its physical temperature $(T)$. However, natural objects emit only some fraction of the radiation which would result from a perfect emitter at a given physical temperature. This fraction defines the emissivity $(e)$ of the object. In the microwave region, $e=T_{\mathrm{b}} / T$, which is a basic equation of passive microwave radiometry (Zwally and Gloersen, 1977).

The usefulness of microwave radiometry as a remote sensing tool results from the fact that the emissivity of an object depends on its physical composition and structure. Microwave emission from a layer of snow consists of both emission from the snow volume itself, as well as emission from the underlying ground. Ice particles within the snow cover act as scatering centers for the microwave radiation. This scattering, which redistributes the upwelling radiation according to snow thickness (number of grains) and crystal size, provides the physical basis for snow measurements using microwave remote sensing.

The ability to distinguish between a snow-covered and a snow-free surface results from the scattering of the microwave radiation by the snow grains. For a snowcovered surface, $T_{\mathrm{b}}$ decreases with increasing snow thickness and grain-size. This general relationship provided the basis for the early analysis of snow depth and snow water equivalent using passive microwave radiometer data. Estimated snow depths for the Canadian high plains and Russian steppe compared favorably with ground observations (Rango and others, 1977).

\section{SNOW GRAIN SIZE DISCUSSION}

Grain-size is often considered a primary feature in the 
description of deposited snow, but due to the highly irregular shapes typically encountered, no generally accepted method to determine the effective grain-size in a snow cover has evolved. Attempts to develop the necessary techniques are underway (Davis and Dozier, 1989). However, these methods may not be applicable for operational field measurements. For most field studies, visual estimates using millimeter grids and hand lenses are still being used. For example, the IAHS International Classification for Seasonal Snow on the Ground (Colbeck and others, 1990) suggests that the observer obtain a "more or less homogeneous mass of snow and record the average size of its prevailing or characteristic grains, the size of the grain or particle being its greatest extension (diameter) measured in millimeters".

While the above method may be adequate for certain types of field studies, the application of passive microwave remote sensing at the regional to hemispheric scale requires the characterization of average snow grain-size over large areas $\left(>100000 \mathrm{~km}^{2}\right)$. This is necessary because algorithms used to extract snow-cover information are sensitive not only to total snow mass, but also to grain-size (Chang and others, 1981). Therefore, in order to develop regional to hemispheric scale snow-cover algorithms (Armstrong and Hardman, 1991), it is necessary to assign an average grain-size derived from regional-scale variables. In addition, it should be noted that in terms of satellite remote sensing, the spatial variation in grain-size would essentially be averaged over the total pixel area (approximately $1000 \mathrm{~km}^{2}$ in the case of the current satellite-borne Special Sensor Microwave Imager or SSM/I) thus reducing the effect of any extreme variations which might exist on a local scale.

The passive microwave brightness temperature of snow-covered terrain is influenced by numerous factors other than amount and structure of the snow, including soil properties, vegetative cover and atmospheric conditions (Foster and others, 1984). However, to apply snowcover algorithms successfully, it is necessary first to evaluate the influence of the most important independent variables on the derived snow-cover values. The purpose of this study is to begin to develop a method to characterize snow-cover grain-size in order to increase the retrieval accuracy of passive microwave algorithms.

The dependence of $T_{\mathrm{b}}$ on grain-size results from the fact that an increase in grain-size increases the scattering cross-section, thus lowering the microwave brightness temperature. Without regard for grain-size variation, this increased scattering and lower brightness temperature would imply an increase in snow amount. Based on the Mie scattering theory and radiative transfer calculations, scattering is highly sensitive to changes in grain-size (Fig.1, Chang and others, 1981). Changes in mean grain diameter of $0.4 \mathrm{~mm}$ (from $0.6 \mathrm{~mm}$ to $1.0 \mathrm{~mm}$ ) would produce a brightness temperature change of more than $50 \mathrm{~K}$. In Figure 1 it can be seen that given a brightness temperature of $175 \mathrm{~K}$, for example, the estimated snow water equivalent could vary by a factor of $4(0.1-0.5 \mathrm{~m})$ for a mean diameter change of $0.4 \mathrm{~mm} \quad(0.6 \mathrm{~mm}$ to $1.0 \mathrm{~mm})$. Such a range of water equivalent values covers a large portion of the total sensitivity range of typical snowcover algorithms. Therefore, without detailed stratigraphic mean grain-size information, to a precision of

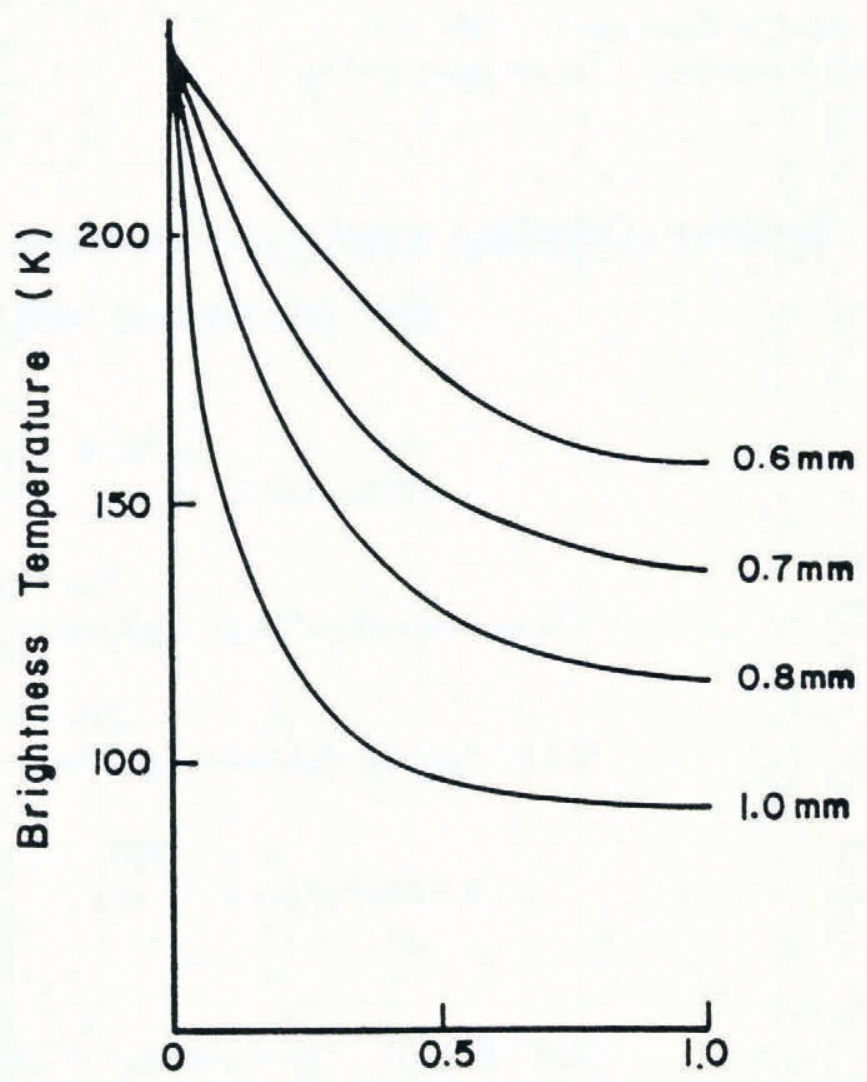

Snow Water Equivalent (m)

Fig. 1. Calculated relationship between $37 \mathrm{GHz}$ brightness temperature (vertical polarization) and snow water equivalent ( $m$ ) as a function of snow grain diameter (mm) (from Chang and others, 1981).

approximately $0.1 \mathrm{~mm}$, accurate snow water equivalent estimates from microwave remote sensing are difficult. In fact, such detailed snow structure information for areas the size of a SSM/I pixel would simply be impossible to obtain. However, even though algorithms are typically applied without consideration for the variable grain-sizes found in the natural snow cover, some success has been reported by each investigator (e.g. Kunzi and others, 1982; Hallikainen and Jolma, 1986; Chang and others, 1987a; Goodison, 1989; Aschbacher, 1989; Rott and others, 1991). This might suggest that the mean grain-size varies for different regions, yet variations over large microwave pixels could be relatively small.

In spite of the strong dependency of grain-size, results have been reasonable under a wider range of conditions than might have been expected considering theory alone. The exact reason for this is not currently well understood. The fact that the spherical grains used in the theoretical calculations are more sensitive to grain-size variation than the more irregular grain shapes found in the natural snow cover may be a partial explanation for the general success of the algorithms (Chang and others, 1976). In addition, the basic assumptions in the scattering theory applied to modeling the natural snow cover are being re-evaluated. In a dense medium with an appreciable fractional volume of scatterers, the assumption of independent scatters used in conventional radiative transfer theory is not rigorous. 


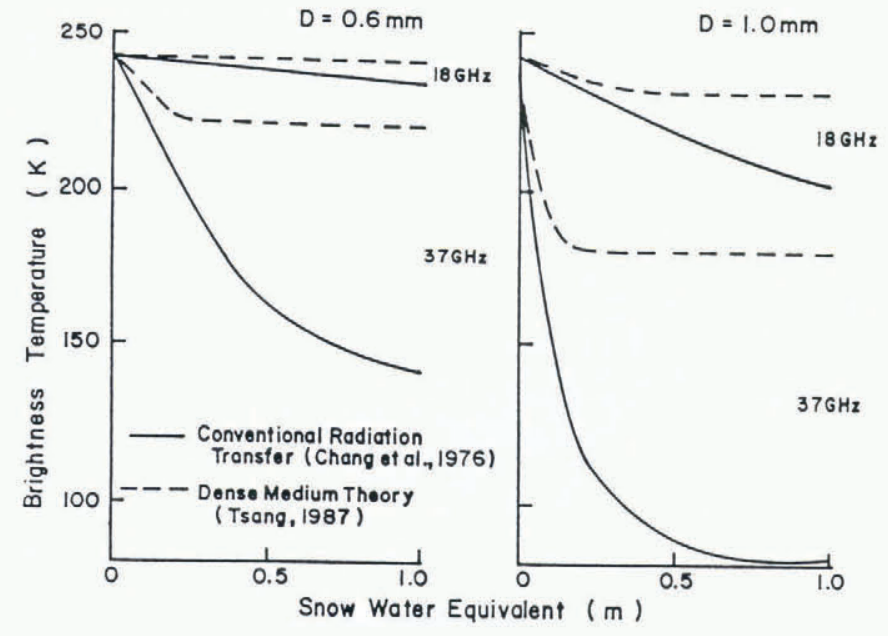

Fig. 2. Calculated brightness temperature $(K)$ as a function of snow water equivalent $(\mathrm{cm})$ and frequency ( $\mathrm{GHz}$, horizontal polarization) using dense medium radiative transfer theory compared to conventional radiative transfer theory.

This has been verified by controlled laboratory experiments (Ishimaru and Fuga, 1982) and has been studied theoretically by Tsang and others (1987) and Wen and others (1990). Recently a dense medium radiative transfer theory which accounts for correlated scattering has been developed (Tsang, 1987). Based on the field theory and using the quasi-crystalline approximation of the Bethe-Salpeter equation, emerging microwave radiation from a closely packed snow cover has been calculated. Figure 2 shows the calculated brightness temperatures from a snow cover for 18 and $37 \mathrm{GHz}$ radiation based on the dense medium theory compared to the results of earlier work (Chang and others, 1987a). The snow density is $300 \mathrm{~kg} \mathrm{~m}^{-3}$ and the selected mean grain diameters are 0.6 and $1.0 \mathrm{~mm}$. In both cases, as the snow water equivalent increases the brightness temperature decreases. However, the dense medium theory predicts a less steep drop in brightness temperature as compared with the conventional radiative transfer calculations. The calculated brightness temperatures for $37 \mathrm{GHz}$ saturate at about 0.2 to $0.3 \mathrm{~m}$ snow water equivalent. This is consistent with results from an earlier experiment using truck-mounted microwave sensors (Chang and others, 1980).

It has been shown that conditions clearly exist where the assumption of a single grain-size will cause significant retrieval errors. For example, Hall and others (1986), Josberger and others (1989) and Chang and others (1987b) found that when the snow cover was composed primarily of large-grained "depth hoar", the standard algorithms tended to greatly overestimate snow amount. Although no quantitative observations regarding grainsize were provided in these references, it was assumed that the overestimation of snow amount was primarily due to the direct relationship between grain-size and increased scattering.

Depth hoar is characterized by large faceted grains which grow in the presence of strong temperature gradients. The presence of a temperature gradient within the snow cover is caused by the ground temperatures being higher than the typical air temperatures above the snow surface. The temperature gradient produces an associated vapor pressure gradient which results in the movement of water vapor upwards through the porous snow layer. When water vapor from the warmer layers comes in contact with the adjacent colder grains, the vapor is deposited on the colder surface. If the temperature/vapor pressure gradient and associated vapor flux are large enough, the deposition is preferential, thus producing the characteristic faceted depth-hoar crystal (Colbeck, 1990). This more rapid form of snowcrystal growth has been reffered to as kinetic growth (Colbeck, 1987). Snow grains which metamorphose in the presence of weaker temperature gradients and lower vapor flux rates tend to have a smooth and rounded texture. However, most important for this study, such grains typically do not grow to diameters which exceed about $1.0 \mathrm{~mm}$ (Armstrong, 1985).

The rapid formation of depth hoar in a seasonal snow cover typically occurs when the temperature gradients exceed $10^{\circ} \mathrm{C} \mathrm{m}^{-1}$ and average snow temperatures are near $0^{\circ} \mathrm{C}$ (Figure 3; Armstrong, 1985). Because a change in either snow depth or average air temperature will affect the temperature gradient in the snow cover, it is important to note that of the two, snow depth typically exhibits greater long-term variability (Armstrong and Armstrong, 1987).

In geographic regions where the seasonal snow-cover depths commonly exceed $0.5-1.0 \mathrm{~m}$, the extent to which large depth-hoar grains are present is controlled primarily by the magnitude of the temperature gradients during early winter. However, by the time the lower portion of the snow cover has developed depth-hoar grains which exceed $2.0 \mathrm{~mm}$ in diameter, the uppermost layers of deepening snow cover are typically metamorphosing in the absence of a strong gradient (Armstrong, 1981). This occurs because the temperature difference is now

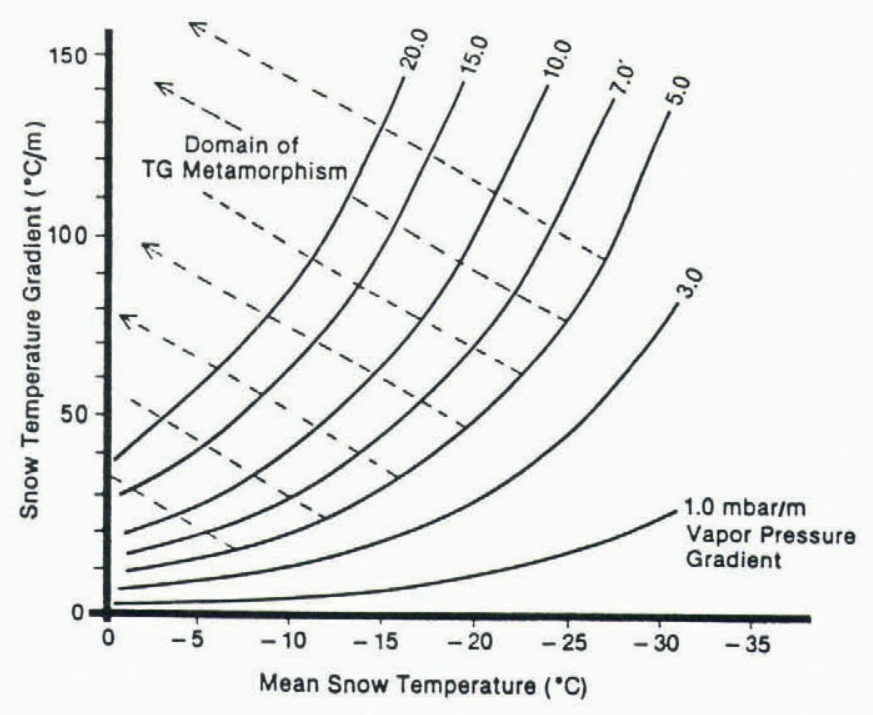

Fig. 3. Relationship between saturation vapor pressure gradient, temperature gradient, and mean temperature within the pore space of a snow cover. The value of $5.0 \mathrm{mbar} \mathrm{m}^{-1}$ is considered here to be the lower limit for temperature-gradient (kinetic) metamorphism. 
averaged over a greater thickness and thus the average gradient is reduced. Therefore, although the average grain-size of the individual depth-hoar layers lower in the snow cover might be large, the average grain-size for the total snow cover remains below the approximate threshold value of $2.0 \mathrm{~mm}$. This condition may cause a normalizing effect and thus provide at least a partial explanation as to why algorithms which apply a single grain-size seem to perform well under a wide range of conditions. Exceptions to this would be the shallow cold snow of the Arctic and sub-Arctic (Benson and Trabant, 1972) and those periods at mid-latitudes when snow depths remain well below normal well into the winter season. Such conditions would cause the depth-hoar crystal form to dominate in the snow cover, resulting in average grain-sizes exceeding $2.0 \mathrm{~mm}$.

In summary, conditions which produce large average grain-sizes may result from two general snow-climate patterns. In one case, the typical winter snow cover may be shallow (less than approximately $0.5-1.0 \mathrm{~m}$ ) combined with mean monthly temperatures consistently less than $10.0^{\circ} \mathrm{C}$, causing the development of depth-hoar grains throughout the snow cover. The second case occurs as an exception within the pattern where mean monthly air temperatures are approximately $-10.0^{\circ} \mathrm{C}$, but snow depths typically exceed $0.5-1.0 \mathrm{~m}$ by early- to midwinter, thus preventing the temperature gradients necessary to produce depth-hoar grains throughout the total snow cover. During exceptional drought years at these locations, snow depths will often not exceed the 0.5$1.0 \mathrm{~m}$ range, and the resulting strong temperature gradients are sufficient to convert the entire snow thickness to depth hoar. An example of such an event is described in the following section.

What is implied here is that, for a given snow climate or region, as a first approximation, there is some rough correlation between depth and average grain-size. If a relationship between regional scale snow-climates and the associated potential to produce a snow cover primarily composed of depth-hoar grains can be established, it would be possible to develop a method to adjust the microwave algorithms for grain-size.

\section{ANALYSIS OF FIELD DATA}

Preliminary investigation of the relationship between snow depth and average grain-size has been undertaken using stratigraphic snow-pit data from field measurements made by the U.S. Geological Survey (USGS) and cooperating agencies, Upper Colorado River Basin (Josberger and Beauvillain, 1989; Josberger and others, 1989); the University of Colorado, Red Mountain Pass, Colorado (Armstrong, 1987); the Canadian Atmospheric Environment Service, Manitoba and Saskatchewan (Goodison, 1989); and the Swiss Federal Institute for Snow and Avalanche Research (personal communication from W. Good and P. Foehn, 1991).

A weighted mean grain-size was computed for each snow pit by multiplying the observed grain-size (diameter, $\mathrm{mm}$ ) within an individual layer by the per cent of total snow-cover thickness represented by that layer and then summing the layer values. For example,

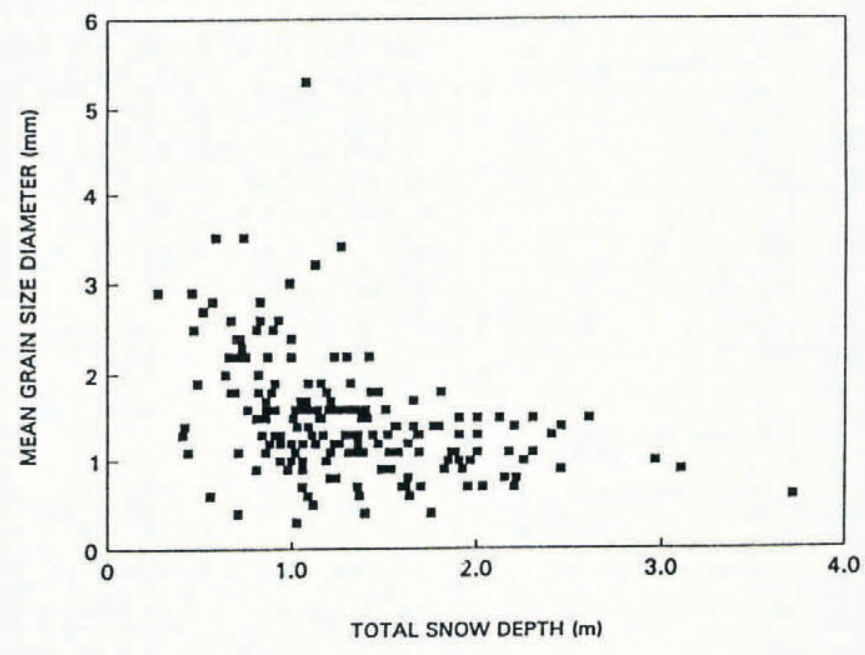

Fig. 4. Relationship between mean snow grain diameter and snow depth for the full Upper Colorado River Basin data set (1984-88).

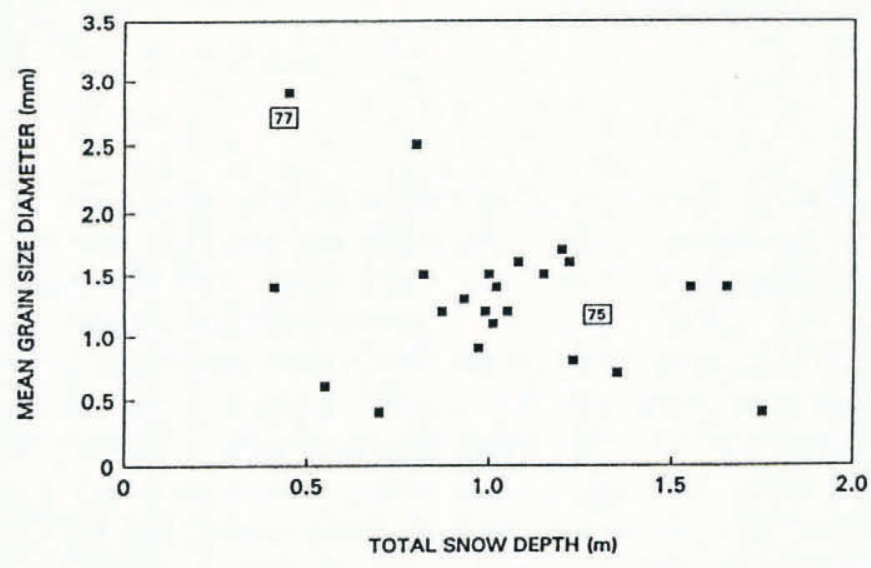

Fig. 5. Relationship between mean snow grain diameter and snow depth for the Fanuary data contained in Figure 4. The notation " 75 " and "77" in Figures 5-7 indicates data points from the Red Mountain Pass data set which represent seasonal snow-depth extremes as described in the text.

the mean grain-size for the entire USGS sample obtained during the period 1984-88 in the Upper Colorado River Basin was $1.4 \mathrm{~mm}$ (diameter) with a standard deviation of $0.5 \mathrm{~mm}$. The Red Mountain Pass data for the years 1972 77 provided a mean diameter of $1.0 \mathrm{~mm}$ and a standard deviation of $0.3 \mathrm{~mm}$. This relatively small standard deviation would indicate that it is appropriate to characterize the stratigraphic grain diameters of the total snow cover with a single mean value.

Figure 4 shows the relationship between mean grainsize (diameter, $\mathrm{mm}$ ) and depth $(\mathrm{m})$ for all data obtained from the Upper Colorado River Basin, and there is no obvious correlation or pattern $\left(r^{2}=0.18\right)$. Figures 5 through 7 contain these data by month. In Figure 5 the data for January do not show a meaningful correlation $\left(r^{2}=0.09\right)$ but a general pattern does emerge which allows some physical interpretation. In most cases the grain-sizes are less than $2.0 \mathrm{~mm}$, although the depths range from less than $0.5 \mathrm{~m}$ to nearly $2.0 \mathrm{~m}$. If our initial 
assumption is correct, we would expect smaller grain-sizes to be associated with depths greater than about 1.0 to $1.5 \mathrm{~m}$. However, in January the mean grain-size is also small where depths are less than $1.0 \mathrm{~m}$. This is probably due to the fact that even in those locations where temperature gradient conditions may favor the growth of larger grains, there has not been sufficient time for this growth to take place and while some grains larger than $2.0 \mathrm{~m}$ may exist at the base of the snow cover, the average size of the total snow cover remains small.

The February data (Fig. 6) show a stronger correlation $\left(r^{2}=0.50\right)$ and again the overall pattern can be interpreted in terms of our knowledge of snow metamorphism. Where snow depths are greater than $1.0 \mathrm{~m}$, the mean grain-sizes have remained less than $2.0 \mathrm{~mm}$, but in the shallower snow, most sites indicate a mean grain-size which exceeds $2.0 \mathrm{~mm}$. At this point in the winter enough time has elapsed for the process of temperature gradient (kinetic) metamorphism to dominate throughout the total stratigraphy of the thinner snow cover, resulting in mean grain diameters which exceed $2.0 \mathrm{~mm}$.

The March (Fig. 7) data set shows a lower $r^{2}$ value of 0.17 and the pattern which existed for the February data is less well defined. In this mid-latitude geographic region (Upper Colorado River Basin), the March data do not offer a good opportunity for analysis because of the frequent occurrence of melt conditions, especially at lower

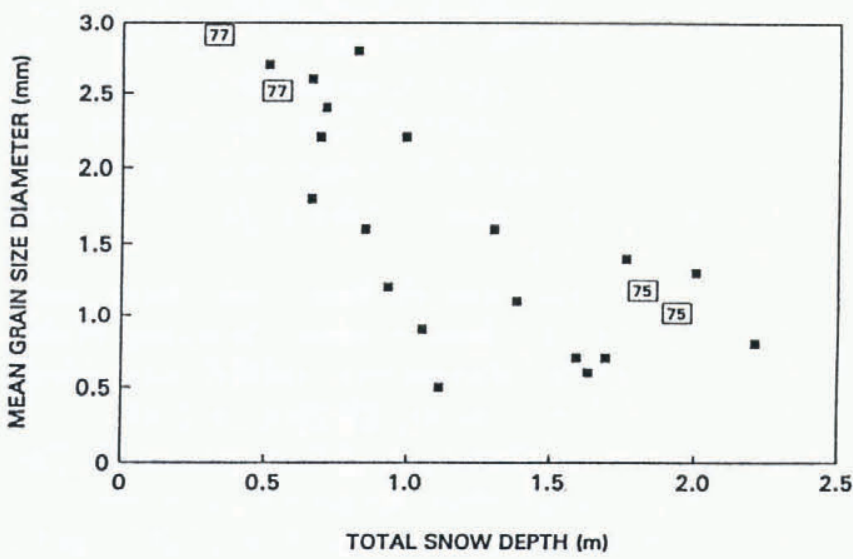

Fig. 6. Relationship between mean snow grain diameter and snow depth for the February data contained in Figure 4.

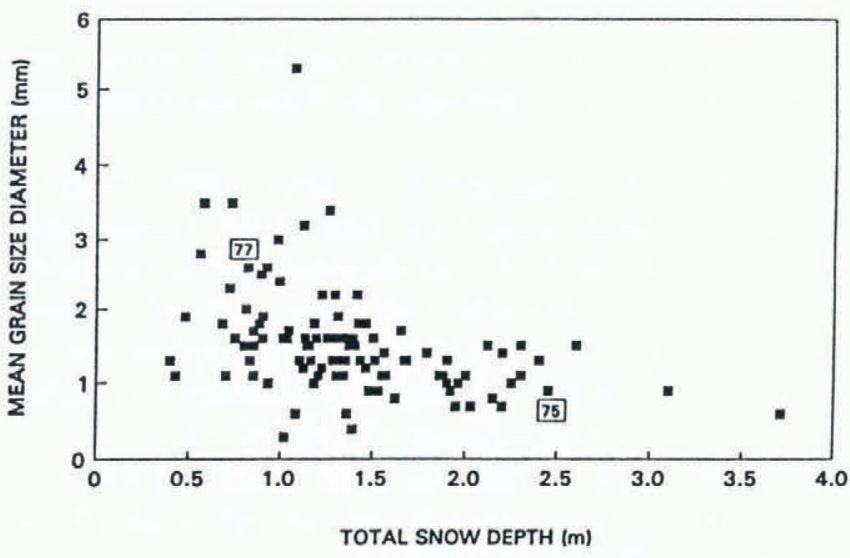

Fig. 7. Relationship between mean snow grain diameter and snow depth for the March data contained in Figure 4. elevation sites. The continued process of melting and refreezing would result in grain growth due to melt-freeze metamorphism (Colbeck, 1987, 1991), a process which is completely independent of the kinetic grain growth process in subfreezing dry snow.

Analysis of data from Canada and Switzerland is still in progress. The data set presented in the preceding figures represents the USGS measurements for the period 1984-88 (irrregular times from late January to early April) from approximately 55 sites in the Upper Colorado River Basin (Josberger and Beauvillain, 1989). These winters represent typical or near-average snow-cover conditions in that no single winter resulted in significant drought or exceptionally deep snow conditions. In order to test the theory of a general relationship between depth and grain-size, it is instructive to introduce additional data into Figures 5-7 which approach seasonal snowdepth extremes. This information is obtained from the University of Colorado, Red Mountain Pass data set (Armstrong, 1987) for the winters of 1977 (drought, 47\% of the 15 year mean) and 1975 (well above normal depths $129 \%$ of the 15 year mean) as indicated by the " 77 " and " 75 " data points in Figures 5-7. These data points define the approximate "end members" for the depth/grain-size relationship. The mean grain-size for the 1977 Red Mountain Pass sample was $2.9 \mathrm{~mm}$ with a standard deviation of $0.4 \mathrm{~mm}$ while for 1975 these values were 1.1 and $0.3 \mathrm{~mm}$ respectively.

\section{CONGLUSIONS}

It is necessary to be able to characterize snow grain-size on a regional basis if the level of accuracy of passive microwave snow-cover algorithms is to be enhanced. To reconstruct the detailed stratigraphy of a regional scale snow cover is not practical. The most basic level of characterization would be to determine, on a regional scale, the extent to which the average snow grain-size exceeds a threshold value of approximately $2.0 \mathrm{~mm}$ in diameter. The preliminary analysis described above indicates that even such a crude relationship between snow depth (subfreezing snow) and grain-size could make a significant contribution to improved algorithm accuracy. Two grain-size data sets have been examined thus far. For the Upper Colorado River Basin, the best empirical regression relationship between snow depth and grain-size occurs in February. February may be the ideal month to establish a relationship because (1) conditions favorable for temperature-gradient metamorphism will have had sufficient time to work, and (2) at high-elevation mountain sites, significant melt metamorphism is unlikely prior to 1 March. More detailed data from Red Mountain Pass, Colorado for two extreme winters seem to fall near the ends of the February Upper Colorado River Basin snow depth/grain-size relationship.

\section{REFERENCES}

Armstrong, R. L. 1981. Some observations on snow cover temperature patterns. Canadian National Research Council. Associate Committee of Geotechnical Research. Technical Memo. 133, 66-81. 
Armstrong, R. L. 1985. Metamorphism in a subfreezing seasonal snow cover. (Ph.D. thesis, University of Colorado, Boulder.)

Armstrong, R. L. 1987. San Juan Mountains avalanche study: evaluation and prediction of avalanche hazard. Annual Report to United States Department of the Interior. Bureau of Reclamation. University of Colorado, Boulder.

Armstrong, R. L. and B. R. Armstrong. 1987. Snow and avalanche climates of the western United States: a comparison of maritime, intermountain and continental conditions. International Association of Hydrological Sciences Publication 162 (Symposium at Davos 1986 Avalanche Formation, Movement and Effects), 281-294.

Armstrong, R. L. and M. Hardman. 1991. Monitoring global snow cover. IGARSS'91. Remote sensing: global monitoring for Earth management. 1991 International Geoscience and Remote Sensing Symposium, Helsinki University of Technology, Espoo, Finland, June 3-6, 1991, 19471950.

Aschbacher, J. 1989. Land surface studies and atmospheric effects by satellite microwave radiometry. (Ph.D. thesis, Leopold-Franzens Universität, Innsbruck.)

Benson, C. S. and D. C. Trabant. 1973. Field measurements on the flux of water vapor through dry snow. International Association of Hydrological Sciences Publication 107 (Symposium at Banff 1972 - Role of Snow and Ice in Hydrology), 291-298.

Chang, T. C., P. Gloersen, T. Schmugge, T. T. Wilheit and H.J. Zwally. 1976. Microwave emission from snow and glacier ice. f. Glaciol., 16(74), 23-39.

Chang, A. T. C., A. Rango and J. C. Shiue. 1980. Remote sensing of snow properties by passive microwave radiometry: GSFC truck experiment. In Rango, A., ed. Microwave remote sensing of snowpack properties. Washington, DC, National Aeronautics and Space Administration, 169-185. (Conference Publication 2153.)

Chang, A. T. C., J. L. Foster, D. K. Hall, A. Rango and B. K. Hartline. 1981. Snow water equivalent determination by microwave radiometry. Greenfield, MD, National Aeronautics and Space Administration. Goddard Space Flight Center. (Technical Memorandum 82074.)

Chang, A. T. C. and 6 others. 1987a. Estimating snowpack parameters in the Colorado River basin. International Association of Hydrological Sciences Publication 166 (Symposium at Vancouver 1987 - Large Scale Effects of Seasonal Snow Cover), 343-352.

Chang, A. T. C., J.L. Foster and D. K. Hall. 1987b. Nimbus-7 SMMR derived global snow cover parameters. Ann. Glaciol., 9, 39-44.

Colbeck, S. C. 1987. A review of the metamorphism and classification of seasonal snow cover crystals. International Association of Hydrological Sciences Publication 162 (Symposium at Davos 1986 - Avalanche Formation, Movement and Effects), 3-34.

Colbeck, S.C. 1991. The layered character of snow covers. Rev. Geophys., 29(1), 81-96.

Colbeck, S. C. and 7 others. 1990. International classification for seasonal snow on the ground. Wallingford, Oxfordshire, IASH.

Davis, R.E. and J. Dozier. 1989. Stereological character- ization of dry alpine snow for microwave remote sensing. Adv. Space Res., 9(1), 245-251.

Foster, J. L., D. K. Hall, A. T. C. Chang and A. Rango. 1984. An overview of passive microwave snow research and results. Rev. Geophys. Space Phys., 22(2), 195-208.

Goodison, B. E. 1989. Determination of areal snow water equivalent on the Canadian prairies using passive microwave satellite data. IGARSS'89. 12th Canadian Symposium on Remote Sensing. Quantitative remote sensing: an economic tool for the nineties, Vancouver, Canada, fuly 10-14, 1989. Volume 3, 1243-1246.

Hall, D. K., A.T.C. Chang and J.L. Foster. 1986. Detection of the depth-hoar layer in the snow-pack of the Arctic coastal plain of Alaska, U.S.A., using satellite data. F. Glaciol., 32(110), 87-94.

Hallikainen, M. T. and P. A. Jolma. 1986. Retrieval of the water equivalent of snow cover in Finland by satellite microwave radiometry. IEEE Trans. Geosci. Remote Sensing, GE-24(6), 855-862.

Ishimaru, A. and Y. Fuga. 1982. Attenuation constant of a coherent field in a dense distribution of particles. $\mathcal{F}$. Opt. Soc. Am., 72, 1317-1320.

Josberger, E. G. and E. Beauvillain. 1989. Snow cover of the upper Colorado River basin from satellite passive microwave and visual imagery. Nord. Hydrol., 20(2), 73-84.

Josberger, E. G., C. H. Ling, W.J. Campbell, P. Gloersen, A. T. C. Chang and A. Rango. 1989. Correlations of Scanning Multichannel Microwave Radiometer (SMMR) observations with snowpack properties of the upper Colorado River basin for Water Year 1986. IGARSS'89. 12th Canadian Symposium on Remote Sensing. Quantitative remote sensing: an economic tool for the nineties, Vancouver, Canada, Fuly 10-14, 1989. Volume 3, 1239-1242.

Kunzi, K. F., S. Patil and H. Rott. 1982. Snow-cover parameters retrieved from Nimbus-7 Scanning Multichannel Microwave Radiometer (SMMR) data. IEEE Trans. Geosci. Remote Sensing, GE-20(4), 452-467.

Rango, A., A. T. C. Chang and J. L. Foster. 1979. The utilization of spaceborne microwave radiometers for monitoring snowpack properties. Nord. Hydrol., 10(1), 25-40.

Rott, H., T. Nagler and J. Aschbacher. 1991. Algorithm development for monitoring global snow cover by spaceborne microwave radiometry. In Proceedings of the 11th EARSeL Symposium, Graz, Austria, 3-5 July 1991. Graz, Joanneum Research, 58-69.

Tsang, L. 1987. Passive remote sensing of dense nontenuous media. F. Electromagnetic Waves and Applications, 1, 159-173.

Tsang, L., J.A. Kong and R. T. Shin. 1987. Theory of microwave remote sensing. New York, Wiley-Interscience.

Wen, B., L. Tsang, D. P. Winebrenner and A. Ishimaru. 1990. Dense medium radiative transfer theory: comparison with experiment and application to microwave remote sensing and polarimetry. IEEE Trans. Geosci. Remote Sensing, GE-28, 46-59.

Zwally, H.J. and P. Gloersen. 1977. Passive microwave images of the polar regions and research applications. Polar Rec., 18(116), 431-450.

The accuracy of references in the text and in this list is the responsibility of the authors, to whom queries should be addressed. 